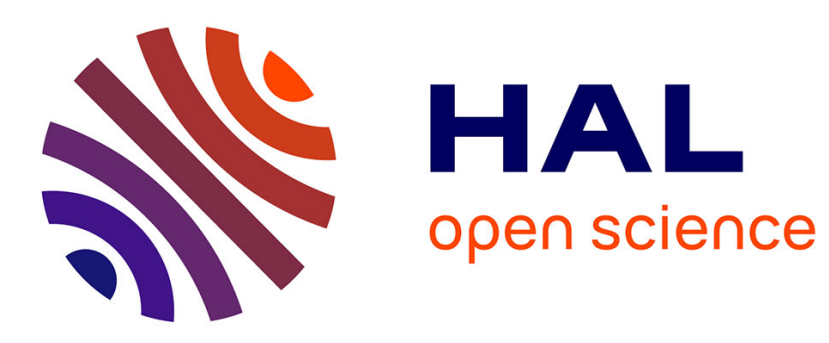

\title{
Pulse Characterization of Optically Triggered SiC Thyristors
}

Nicolas Dheilly, Gontran Pâques, Sigo Scharnholz, Dominique Planson

\section{To cite this version:}

Nicolas Dheilly, Gontran Pâques, Sigo Scharnholz, Dominique Planson. Pulse Characterization of Optically Triggered SiC Thyristors. Materials Science Forum, 2012, 717-720, pp.1179-1182. 10.4028/www.scientific.net/MSF.717-720.1179 . hal-02166420

\section{HAL Id: hal-02166420 \\ https://hal.science/hal-02166420}

Submitted on 26 Jun 2019

HAL is a multi-disciplinary open access archive for the deposit and dissemination of scientific research documents, whether they are published or not. The documents may come from teaching and research institutions in France or abroad, or from public or private research centers.
L'archive ouverte pluridisciplinaire HAL, est destinée au dépôt et à la diffusion de documents scientifiques de niveau recherche, publiés ou non, émanant des établissements d'enseignement et de recherche français ou étrangers, des laboratoires publics ou privés. 


\title{
Pulse characterization of optically triggered SiC thyristors
}

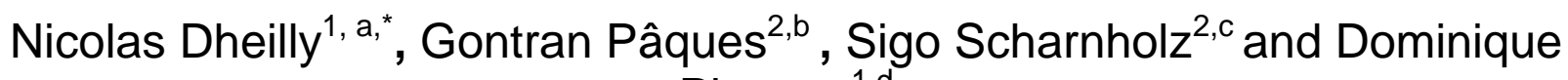 Planson ${ }^{1, d}$}

${ }^{1}$ Université de Lyon, INSA de Lyon, Ampère Laboratory, UMR 5005, 20 avenue A. Einstein, F69621 Villeurbanne Cedex, France

${ }^{2}$ French-German Research Institute of Saint-Louis (ISL), 5 rue du Général Cassagnou, 68301 Saint Louis cedex, France

nicolas.dheilly@insa-lyon.fr, ${ }^{b}$ gontran.paques@rwth-aachen.de, csigo.scharnholz@isl.eu dominique.planson@insa-lyon.fr,

Keywords: Silicon carbide, Light triggered thyristor, LTT, pulse power.

\begin{abstract}
This paper deals with the pulse capabilities of $4 \mathrm{H}-\mathrm{SiC}$ optically triggered thyristors. The device structure and the fabrication process are presented. The results of pulse characterizations are shown. Two types of current pulses were used, a short (pulse width of $10 \mu \mathrm{s}$ ) and a long (pulse width of $650 \mu \mathrm{s}$ ). Peak current densities of $17 \mathrm{kA} \cdot \mathrm{cm}^{-2}$ and $4 \mathrm{kA} \cdot \mathrm{cm}^{-2}$ were attained with short and long pulses respectively. The failures and degradation caused by these experiments are also shown in this paper.
\end{abstract}

\section{Introduction}

To further improve the performance and to reduce weight and volume of switches developed for future electromagnetic weapon and protection systems, research laboratories like ARL or ISL evaluate the pulsed power capability of $\mathrm{SiC}$ thyristors [1,2]. In the field of pulse power electronics, the thyristor is best suited because of its high blocking voltage and high current handling capability due to the bipolar conduction.

We have lately demonstrated light triggering of SiC thyristors with a UV LED [3, 4]. The advantages of the light triggered thyristor (LTT) are the galvanic isolation of the driver and the reduction of EMI interferences, which are interesting for high voltage systems. A second run of LTT has been designed and fabricated. This paper reports on the evaluation of these devices for pulse power applications. First, the structure and the fabrication of the device are detailed. Then, pulse experiments performed on the thyristors are detailed, and finally the results including degradation phenomena induced by the current pulses are shown and explained.

\section{Device structure and fabrication}

The material used for the fabrication of the thyristors was purchased from Cree, Inc. It is an $8^{\circ}$ offaxis $4 \mathrm{H}-\mathrm{SiC} \mathrm{N}+$ substrate covered by 4 epi-layers $(\mathrm{P} / \mathrm{P}-/ \mathrm{N} / \mathrm{P}+)$ forming an asymmetrical thyristor structure. The thickness of the P-type buffer and drift layer are respectively $1 \mu \mathrm{m}$ and $60 \mu \mathrm{m}$ and their doping concentration are respectively $4.2 \times 10^{17} \mathrm{~cm}^{-3}$ and $10^{15} \mathrm{~cm}^{-3}$. The N-type gate layer is $3 \mu \mathrm{m}$ thick and is doped at $10^{17} \mathrm{~cm}^{-3}$. The P-type anode layer has a thickness of $2 \mu \mathrm{m}$ and a doping concentration of $10^{19} \mathrm{~cm}^{-3}$. The active area of the thyristor is $1 \mathrm{~mm}^{2}$ and the total area is $2.35 \mathrm{~mm}^{2}$ including the edge termination.

Three successive RIE (Reactive Ion Etching) etching steps were used to form the edge termination, which is an etched guard rings assisted JTE (Junction Termination Extension). No ion implantation were employed to build the thyristors to avoid degradations of the material related to this fabrication process.

A $\mathrm{Ti} / \mathrm{Ni}$ metallization was deposited on the backside and annealed at $950^{\circ} \mathrm{C}$ for 2 minutes to form an ohmic cathode contact. Three metal layers $\mathrm{Ni} / \mathrm{Ti} / \mathrm{Al}$ annealed at $850^{\circ} \mathrm{C}$ for 2 minutes were 
then used to obtain an ohmic contact to the $\mathrm{P}+$ anode layer. Specific resistance of the anode contact was estimated to $2-3 \times 10^{-4} \Omega . \mathrm{cm}^{2}$ with the TLM (transfer length method). A $1.5 \mu \mathrm{m}$ thick Ti/Ni/Au overmetallization was deposited on the anode. The involute pattern of the anode metallization allows anode and openings fingers to have the same width on most part of the device. This theoretically ensures a good turn on homogeneity in the thyristor.

The thyristors were then diced into die and attached to a PCB substrate using silver paste. The anode contact was bonded with gold wires having a diameter of $25 \mu \mathrm{m}$.

Static characterizations of these thyristors exhibit a best blocking voltage of $6.3 \mathrm{kV}$ and a specific differential on-state resistance of $6 \mathrm{~m} \Omega . \mathrm{cm}^{2}$.

\section{Pulse characterizations}

Characterizations with a short $(10 \mu \mathrm{s}$ width $)$ and a long $(650 \mu \mathrm{s}$ width) current pulse were performed on the thyristors with a homemade package.

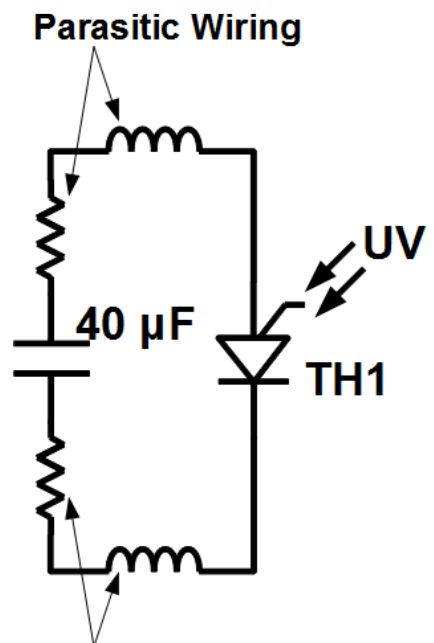

Parasitic Wiring

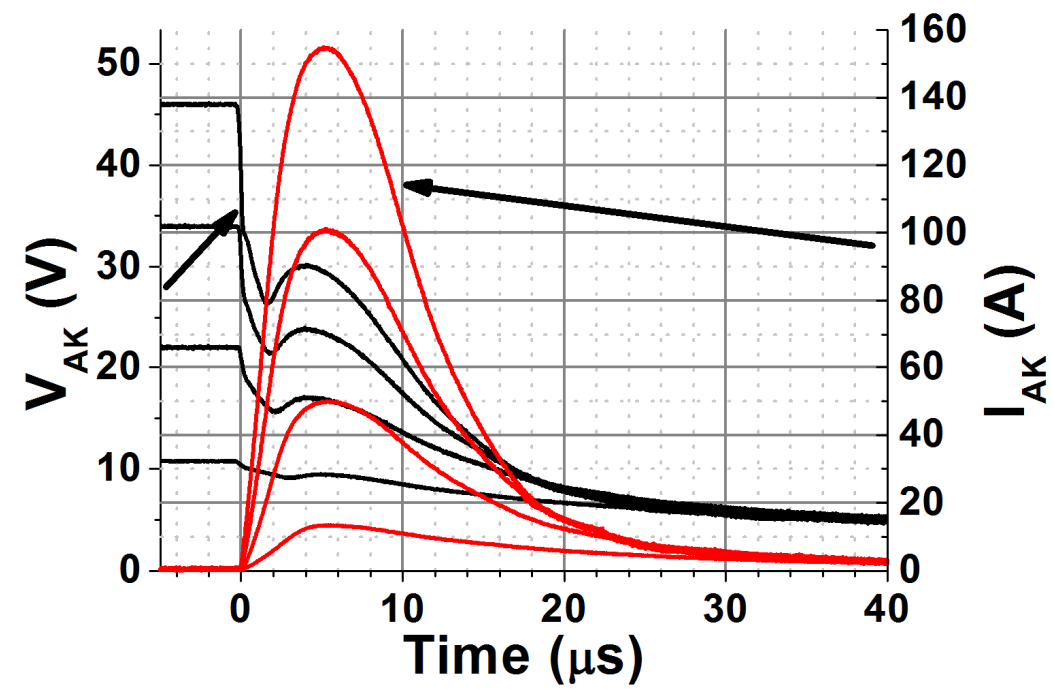

Fig. 1. Schematic of the Fig. 2. Voltage and current waveforms of the thyristor stressed experiment for short pulse with short pulses.

characterization.

Short Pulse. To perform short pulse measurements, the thyristor under test (TH1) was used to control the discharge of a capacitor through a shortcut. The schematic of this experiment is depicted in Fig. 1. A light source including a UV LED (Light Emitting Diode) emitting at a wavelength of $365 \mathrm{~nm}$ was previously developed to trigger the device [3]. Thyristor current and voltage waveforms resulting from the discharge are shown in Fig. 2. Several successive pulses were applied to the device, increasing between each shot the capacitor charging voltage. The device under test was able to generate current pulses having a peak value of up to

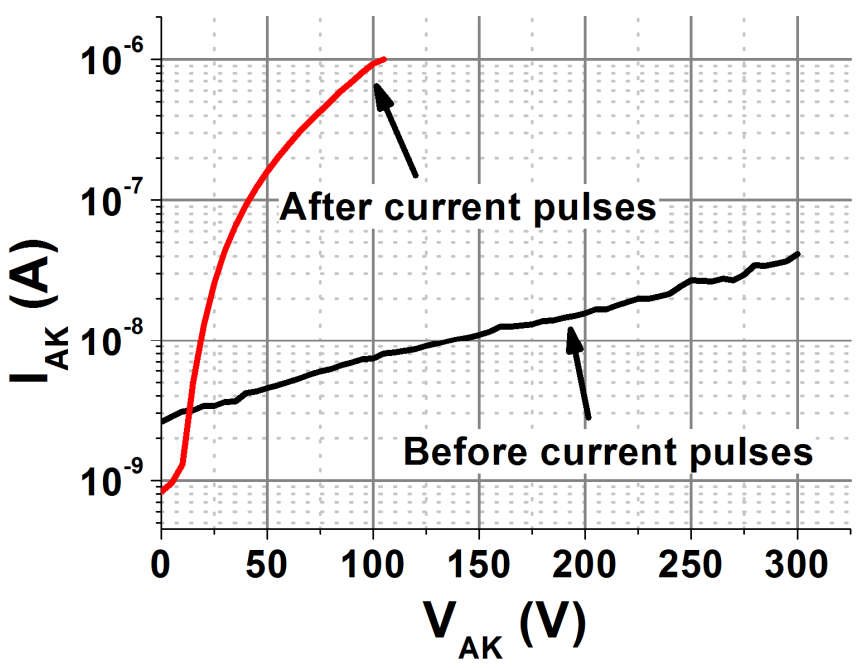

Fig. 3. Blocking characteristics of a thyristor before and after short pulse characterization, showing the degradation of the device. 
$156 \mathrm{~A}$. This value corresponds to a current density of $15.6 \mathrm{kA} . \mathrm{cm}^{-2}$ in the active area. After this last pulse, the device was not able to switch on again and the direct blocking characteristic of the device was severely degraded (see Fig. 3). A possible explanation is the bipolar degradation of the device due to the high current density that occurred.

To further investigate this point, short pulse characterizations were performed on a second thyristor. The on-state characteristic was measured after a series of five current pulses with equal peak current, to see if the differential resistance increases, revealing bipolar degradation. Series with a peak current of $60 \mathrm{~A}, 80 \mathrm{~A}, 100 \mathrm{~A}, 120 \mathrm{~A}, 130 \mathrm{~A}, 145 \mathrm{~A}, 160 \mathrm{~A}$ and $170 \mathrm{~A}$ were applied to the thyristor under test. No particular drift in the on-state differential resistance was observed between these pulse series. The forward voltage drop at $100 \mathrm{~A} . \mathrm{cm}^{-2}$ showed no significant change and was between $3.7 \mathrm{~V}$ and $3.9 \mathrm{~V}$. The device failed in the same manner as the first one, showing also a degradation of its blocking characteristic. The two devices tested with short current pulses failed at approximately the same peak current density. However to see evidence of bipolar degradation in these thyristors, longer stress tests with lower peak current may be necessary.

The maximum current density obtained with these devices on short pulse is $17 \mathrm{kA} . \mathrm{cm}^{-2}$ which is lower than $38 \mathrm{kA} . \mathrm{cm}^{-2}$, the best performance reported on $\mathrm{SiC}$ thyristors with similar pulse length [5]. Nevertheless, the drift layer thickness of the thyristors in [5] must be thinner since they are $1 \mathrm{kV}$ devices.

Long pulse. To carry out long pulse characterization, the discharge of the same capacitor in an inductive load was studied. The schematic of this experiment is shown in Fig. 4. Three diodes were included in the circuit in order to avoid reverse current to flow in the thyristor and to limit the reverse voltage applied to the thyristor. The pulse obtained with this circuit is depicted in Fig. 5, and its width was $650 \mu \mathrm{s}$. With a capacitor charging voltage of $355 \mathrm{~V}$, a peak current of $40 \mathrm{~A}$ was reached, corresponding to a current density of $4 \mathrm{kA} . \mathrm{cm}^{-2}$. Eleven successive pulses, similar to the one represented in Fig. 5, were generated by triggering the thyristor. This experiment led to the destruction of the metallization and of some of the wire bonding connections.

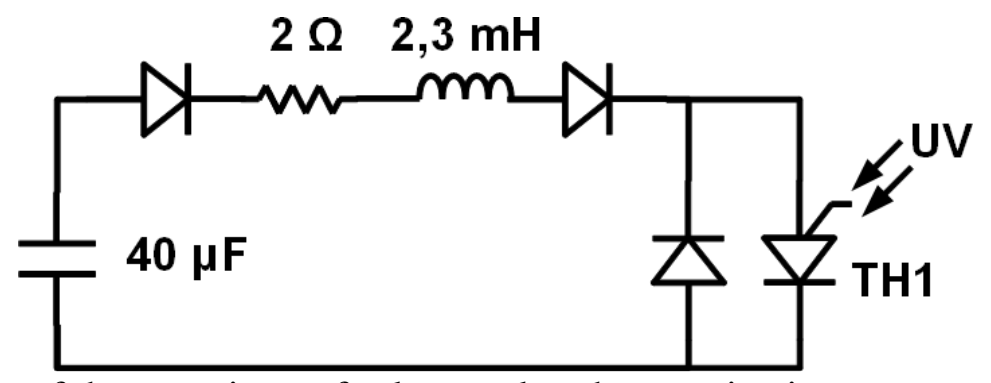

Fig. 4. Schematic of the experiment for long pulse characterization.

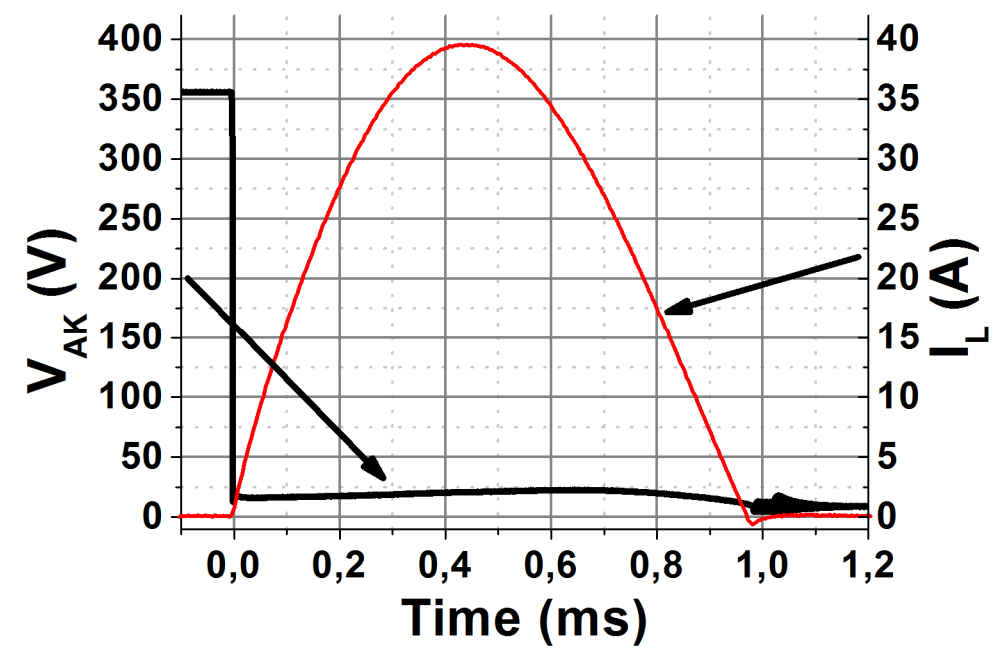

Fig. 5. Voltage and current waveforms of the thyristor stressed with a long current pulse. 
A picture of the device after this test is shown in Fig. 6. Subsequently to the eighth pulse, the lower left anode bondings were melted. Three more shots were conducted before the total destruction of the device. After the eleventh pulse, the upper left bondings were also melted. To reach the left part of the device, the current must have flown from the right part of the thyristor to the left through the narrow paths in the middle of the device. The very high current density in the metallization has led to the destruction of the metallization and the device. To obtain better performances with long pulses, the packaging must be improved.

The result shown in this paper is close to the highest current density reported for similar pulse width with $\mathrm{SiC}$ thyristors, which is $4.2 \mathrm{kA} \cdot \mathrm{cm}^{-2}$ [1].

\section{Summary}

4H-SiC Silicon carbide light triggered thyristors were fabricated to investigate their performances in terms of their pulse current capability. Two types of current pulses were used to test the devices. With the short one (10 $\mu \mathrm{s}$ width), a peak current density of $17 \mathrm{kA} \cdot \mathrm{cm}^{-2}$ was attained before failure. The device under test was not able to switch on anymore and the blocking characteristic was degraded. Another short pulse experiment was conducted to show evidence of bipolar degradation but this test was not conclusive. Concerning the long pulse test (10 $\mu$ s width), a peak current density of $4 \mathrm{kA} . \mathrm{cm}^{-2}$ was reached, which is close to the state of the art of electrically triggered $\mathrm{SiC}$ thyristors. After these tests, failures of the wire bonds and the metallization were clearly identified.

\section{References}

[1] H. O'Brien, W. Shahen, V. Chiscop, C. Scozzie, and M. Koebke, Evaluation of Si and SiC SGTOs for High-Action Army Applications, IEEE Trans. on Magnetics 45(1), p. 402 (2009)

[2] S. Scharnholz, B. Vergne, J.-P. Konrath, G. Pâques, and V. Zorngiebel, Pulse current characterization of SiC GTO thyristors, Material Science Forum vol. 679-680, p. 682 (2011).

[3] N. Dheilly, G. Pâques, D. Planson, P. Bevilacqua, S. Scharnholz, Optical Triggering of 4H-SiC Thyristors with a 365 nm UV LED, Material Science Forum, vol. 679-680, p. 690 (2011)

[4] N. Dheilly, G. Pâques, S. Scharnholz, P. Bevilacqua, C. Raynaud, D.-M. Nguyen, R.W. De Doncker, and D. Planson, Optical triggering of SiC thyristors using UV LEDs, Electronics Letters, vol. 47, no. 7, p. 459 (2011)

[5] H. O'Brien, W. Shahen, and S. Bayne, Evaluation of $4 \mathrm{~mm} \times 4 \mathrm{~mm}$ Silicon Carbide Thyristors, IEEE Transactions on Dielectrics and Electrical Insulation, vol. 14, p. 986 (2007) 